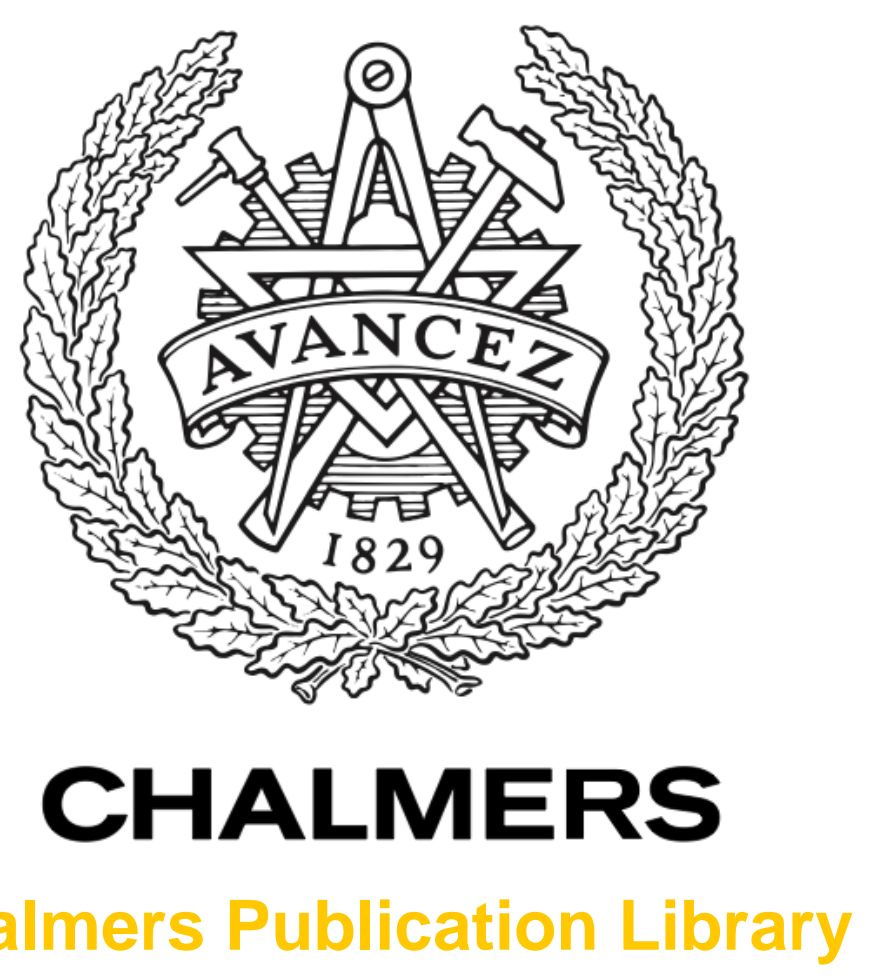

Challmers Publication Library

Participation in sanitation planning in Burkina Faso: theory and practice

This document has been downloaded from Chalmers Publication Library (CPL). It is the author's version of a work that was accepted for publication in:

Journal of Water Sanitation and Hygiene for Development (ISSN: 2043-9083)

Citation for the published paper:

McConville, J. ; Kain, J. ; Kvarnstrom, E. et al. (2014) "Participation in sanitation planning in Burkina Faso: theory and practice". Journal of Water Sanitation and Hygiene for

Development, vol. 4(2), pp. 304-312.

http://dx.doi.org/10.2166/washdev.2014.125

Downloaded from: http://publications.lib.chalmers.se/publication/204095

Notice: Changes introduced as a result of publishing processes such as copy-editing and formatting may not be reflected in this document. For a definitive version of this work, please refer to the published source. Please note that access to the published version might require a subscription.

Chalmers Publication Library (CPL) offers the possibility of retrieving research publications produced at Chalmers University of Technology. It covers all types of publications: articles, dissertations, licentiate theses, masters theses, conference papers, reports etc. Since 2006 it is the official tool for Chalmers official publication statistics. To ensure that Chalmers research results are disseminated as widely as possible, an Open Access Policy has been adopted.

The CPL service is administrated and maintained by Chalmers Library. 


\section{Journal of Water, Sanitation and Hygiene for Development Participation in Sanitation Planning in Burkina Faso: Theory and Practice --Manuscript Draft--}

Manuscript Number:

Full Title:

Short Title:

Article Type:

Corresponding Author:
Participation in Sanitation Planning in Burkina Faso: Theory and Practice

Participation in Sanitation Planning in Burkina Faso: Theory and Practice

Research Paper

Jennifer R. McConville, PhD

Chalmers University of Technology

Göteborg, SWEDEN

Chalmers University of Technology

Corresponding Author's Institution

Corresponding Author's Secondary Institution:

First Author:

Jennifer R. McConville, PhD

First Author Secondary Information:

Order of Authors:

Jennifer R. McConville, PhD

Jaan-Henrik Kain, PhD

Elisabeth Kvarnström, PhD

Lukas Ulrich

Order of Authors Secondary Information:

Abstract:

Stakeholder participation is commonly promoted as a means to boost outcomes of sanitation improvement projects, in particular in developing countries. However, there is little research on when or how this participation should occur during the process of planning and implementing a sanitation system in order to maximize the effect. This study develops a framework for analysing participation levels of different stakeholders throughout a planning process and applies it to sanitation planning guidelines and case studies from Burkina Faso. This analysis highlights that, particularly during designing of system options and selecting among these options, there exist potential weaknesses regarding who participates and how that participation may influence what type of sanitation is implemented. 


\title{
Participation in Sanitation Planning in Burkina Faso: Theory and Practice
}

\author{
J. R. McConville**1, J-H. Kain*, E. Kvarnström** and L. Ulrich*** \\ * Department of Architecture, Chalmers University of Technology, 412-96 Göteborg, Sweden \\ (E-mail: jenmcc@chalmers.se; kain@chalmers.se) \\ ** Urban Water Management Sweden AB, Årstaängsvägen 1A, 11743 Stockholm, Sweden \\ (E-mail: elisabeth.kvarnstrom@urbanwater.se) \\ *** Department of Water and Sanitation in Developing Countries (Sandec), Swiss Federal Institute of Aquatic \\ Science and Technology (Eawag), P.O. Box 611, 8600 Duebendorf, Switzerland \\ (E-mail: lukas.ulrich@eawag.ch) \\ ${ }^{1}$ Corresponding author: \\ Jennifer R McConville \\ Chalmers University of Technology, SE-41296 Göteborg, Sweden \\ Tel: +46736729083 \\ E-mail:jenmcc@chalmers.se \\ Website: www.chalmers.se/en/staff/Pages/jenmcc.aspx
}

\begin{abstract}
Stakeholder participation is commonly promoted as a means to boost outcomes of sanitation improvement projects, in particular in developing countries. However, there is little research on when or how this participation should occur during the process of planning and implementing a sanitation system in order to maximize the effect. This study develops a framework for analysing participation levels of different stakeholders throughout a planning process and applies it to sanitation planning guidelines and case studies from Burkina Faso. This analysis highlights that, particularly during designing of system options and selecting among these options, there exist potential weaknesses regarding who participates and how that participation may influence what type of sanitation is implemented.
\end{abstract}

Keywords

Participation, Planning Theory, Planning Practice, Sanitation 


\section{INTRODUCTION}

Stakeholder engagement and participation is a popular concept in many disciplines, from environmental planning and management to international development work. In the field of sanitation, participation is promoted as a tool for overcoming some of the major challenges to improved access to sanitation, such as low demand for sanitation infrastructure, poor hygiene habits, weak institutional structures and low capacity for operation and maintenance of built systems (Wright, 1997; Wood et al., 1998). Stakeholder participation in sanitation planning and implementation is encouraged because it is believed that it will create demand, e.g. toilets that are wanted will be used (Wright, 1997); it will lead to a better decision-making process where the selected technologies are better adapted to the local context (WSSCC/Eawag, 2005); and it will increase stakeholders' capacities to manage the system afterwards (Roma \& Jeffrey, 2010). For reaching the un-served in the sanitation sector, the participation paradigm is now widely accepted and there is increasing promotion of collaborative design and policymaking among academics and politicians as a way to increase sustainability (Murcott, 2007).

Although there is an abundance of empirical evidence from rural sanitation and water projects showing the benefits of participatory processes (e.g. Wright, 1997; Narayan, 1995; WSP, 2007), there has been little research on how different forms of participation affect project outcomes, especially in urban areas. A preliminary exploration found that not all forms of participation are equally influential in delivering successful urban sanitation services (Nance \& Ortolano, 2007). However, Nance \& Ortolano also stated that further studies are needed. Just as sanitation experts talk about unbundling sanitation investments and working along the entire chain of technologies that make up the sanitation system (Wright, 1997), it is now time to start unbundling the planning process in the same manner and raise questions about how participation is promoted and facilitated, as well as when it should take place. 
To address these questions, this study will (i) introduce analytical tools for categorizing participation levels and decision-making domains, (ii) use them to explain how and when participation appears in sanitation planning processes, and (iii) suggest how this knowledge can be used to improve planning processes in terms of more deliberate participation in sanitation planning.

\begin{abstract}
ANALYTICAL FRAMEWORK
In order to assess how participation appears in sanitation projects, this paper develops an analytical framework based on 1) various steps of sanitation planning, 2) a participation ladder to classify levels of participation and 3) different decision-making domains of participating groups of stakeholders. The framework is then employed to analyse the degree of participation in two sanitation planning guidelines (theoretical sanitation planning) and in two case studies in Burkina Faso (practice of sanitation planning). This will facilitate identifying potential weaknesses both in how participation is understood and in how it is implemented, as well as finding opportunities for increasing the benefits from stakeholder participation.
\end{abstract}

\title{
Planning steps
}

This study recognizes that a sanitation planning process is typically made up of a variety of steps and that different stakeholders may be involved to different degrees in each step. Therefore, this paper applies a set of generic planning steps derived from a literature review of the planning frameworks that are currently promoted by various sanitation agencies (McConville, 2008) as the backbone on which to build the analysis. The five generic steps to planning and implementing sanitation projects are (1) Problem identification, (2) Defining objectives, (3) Design options, (4) Selection process, and (5) Action plan for implementation. The analysis uses the generic steps as a backbone structure, so that how planning is done can be assessed within each step in the process. 


\section{Participation ladder}

One of the most influential classifications of participation levels is the participation ladder developed by Arnstein in the 1960s (Arnstein, 1969). Although developed as a critique of top-down urban development projects in the United States, Arnstein's ladder is still widely applied today and often cited as a basis for developing newer participation typologies (e.g. Choguill, 1996; Hamdi \& Goethert, 1997). There is some critique against the continued and sometimes indiscriminate use of Arnstein's ladder after more than 40 years, particularly regarding its failure to capture dynamics and differences between stakeholders (Tritter \& McCallum, 2006). Accordingly, this study is using the ladder, not as a stand-alone classification, but as one of three complementary tools in the ambition to cover all stakeholder groups involved in a sanitation planning process.

There are eight rungs in Arnstein's ladder and each corresponds to a level of stakeholder power in influencing the planning process. The first two rungs are essentially levels of non-participation: (1) Manipulation is when power-holders use stakeholder advisory groups to "rubberstamp" projects for approval without clearly explaining all implications of the project. 2) Therapy strategies in participation involve stakeholders with the hidden purpose of educating them. The next three steps represent participation levels that are tokenistic: (3) Informing essentially means that stakeholders are provided with information regarding the plan, but the information flow is one-way and questions are discouraged. (4) Consultation invites stakeholders to give their opinions, but does not combine the consultation with other mechanisms that will assure that their ideas are taken into account. (5) Placation brings stakeholders one step closer to influence, but still without any rights to decide, e.g. minority representatives on advisory boards. The last three steps of the ladder see increasing degrees of stakeholder power and decision-making influence. (6) Partnership represents a re-distribution of power that results in planning and decision-making being shared between 
stakeholders and power-holders. (7) Delegated Power means that stakeholders or their delegated representatives have significant power to hold authorities accountable for the programs offered. (8) Control is reached when stakeholder groups have direct control over programs/projects without intermediaries between funding sources, planning and implementation. Note that Arnstein's original term at this rung was "Citizen Control", but to accommodate a more differentiated analysis of the participation levels of all involved stakeholders it is here changed to just "Control".

\section{Decision-making domains}

As discussed above, one of the criticisms directed at the Arnstein ladder is that it does not recognise that different user groups may seek involvement in the process at different times and that it offers a simplistic view of citizens as stakeholders (Tritter \& McCallum, 2006). To avoid such simplification, and to capture the dynamics of processes that typically involve more than just citizens and city authorities, this study will look at participation from the perspective of several different stakeholder groups. The definition of these different stakeholder groups is based on the concept of different decision-making domains within the urban sanitation sector. This analysis will use the stakeholder classifications from the IWA specialist group for sanitation in urban areas: (i) Users, (ii) Neighbourhood, (iii) City, and (iv) Beyond the City (IWA, 2006).

\footnotetext{
ANALYSIS AND RESULTS

This analytical framework is applied to two sanitation planning guidelines and two implemented sanitation projects from the field. The two guidelines for sanitation improvement have gained recognition world-wide and are supported by international donors and sanitation research organizations while the two implemented projects have been carried out by two well-respected organizations involved in sanitation provision efforts in Burkina Faso.
} 
The two planning guidelines are Community-Led Total Sanitation (CLTS) and Community-Led Urban Environmental Sanitation (CLUES). The CLTS approach has received much attention as an innovative methodology that has shown positive results in eliminating open defecation (Kar \& Chambers, 2008). Although originally aimed at rural populations, the success of this methodology has led to its application in urban areas (SEI, 2008). CLUES is a multi-sector planning approach geared towards service delivery in poor urban areas and was developed through a collaboration of the Swiss Federal Institute of Aquatic Science and Technology (Eawag), Water Supply and Sanitation Collaborative Council (WSSCC) and UN-HABITAT (Lüthi et al., 2011).

The first example of local practice is the Strategic Plan for Sanitation (PSAO) in the city of Ouagadougou (pop. 1,475,000), which is an on-going government initiated program that is run through the National Office for Water and Sanitation (ONEA) in Burkina Faso. Started in the early 1990s, this program is hailed as a success based on its innovative use of a sanitation surtax to fund on-site sanitation and the large number of latrines constructed (WSP, 2002). The second case highlights the efforts of the inter-state institution CREPA (Centre Régional pour l'Eau Potable et l'Assainissement à faible coût) to provide sanitation services in the small town of Tougan (pop. 16,000) in north-western Burkina Faso. CREPA is the leading applied-research institute for appropriate and affordable sanitation in French-speaking West Africa.

The main stakeholders in each case are shown in Table 1. Information regarding these sanitation projects was gathered from document reviews, interview studies and site visits to the project areas. Case study methodology (Yin, 2003) was applied during data collection and analysis to assure reliability and validity. 
Table 1. Institutional map of the stakeholder domains in the two guidelines (CLTS and CLUES) and the two Burkina Faso field projects (Ouagadougou and Tougan). HH is household

\begin{tabular}{|c|c|c|c|c|c|}
\hline & Users & Neighbourhood & City & Beyond the City & Power-holder \\
\hline CLTS & $\mathrm{HH}$ & $\begin{array}{l}\text { Community } \\
\text { members }\end{array}$ & $\begin{array}{l}\text { Municipal } \\
\text { authorities }\end{array}$ & $\begin{array}{c}\text { Regional/national } \\
\text { authorities }\end{array}$ & $\begin{array}{l}\text { External facilitator \& } \\
\text { support organisation }\end{array}$ \\
\hline CLUES & $\mathrm{HH}$ & Local NGOs/CBOs & $\begin{array}{l}\text { Municipal } \\
\text { authorities }\end{array}$ & $\begin{array}{l}\text { Sector experts, } \\
\text { universities, } \\
\text { regional/national } \\
\text { authorities }\end{array}$ & Municipality or NGO \\
\hline PSAO & $\mathrm{HH}$ & NGOs, technical & Municipal & ONEA, & ONEA \& WSP \\
\hline Ouagadougou & & $\begin{array}{l}\text { offices, masons } \\
\text { social-marketers }\end{array}$ & authorities & $\begin{array}{l}\text { Ministries of Health, } \\
\text { Agriculture \& Water } \\
\text { Resources }\end{array}$ & \\
\hline CREPA & $\mathrm{HH}$ & Women's & Municipal & Decentralized technical & CREPA \\
\hline Tougan & & $\begin{array}{l}\text { associations \& } \\
\text { masons }\end{array}$ & authorities & $\begin{array}{c}\text { services, ONEA, } \\
\text { donors }\end{array}$ & \\
\hline
\end{tabular}

\section{CLTS}

CLTS process is led by an external facilitator who guides the community through three roughly defined steps: Pre-triggering, Triggering, and Post-Triggering (Kar \& Chambers, 2008). During the pre-triggering step the facilitator examines the village to gain a sense of the overall sanitation problems in the community (problem identification). This step is initiated by the facilitator, but community members (Users/Neighbourhood) are invited into the process so as to build trust between the community and the facilitator. In this first twos step City or Regional authorities have been informed of the intervention, but do not participate directly in the CLTS process (Figure 1). After the facilitator has led community members through problem identification, the triggering moment occurs and facilitator can step out of the power-holding role and let the community take 
control of planning. Collective realization of the effects of open-defecation triggers community

The process of designing and selecting technical options, as well as action planning, are labelled as post-triggering follow-up in CLTS language. At this stage the facilitator helps the community to direct the motivation released during triggering into concrete action. CLTS stresses the importance of allowing the community to dictate its own solutions, yet it also recommends working with the proper authorities and encouraging institutional support for training and capacity development (Kar \& Chambers, 2008; Lüthi et al., 2009). Therefore, the level of participation of all various actors in the last three planning steps is most representative of delegated power.

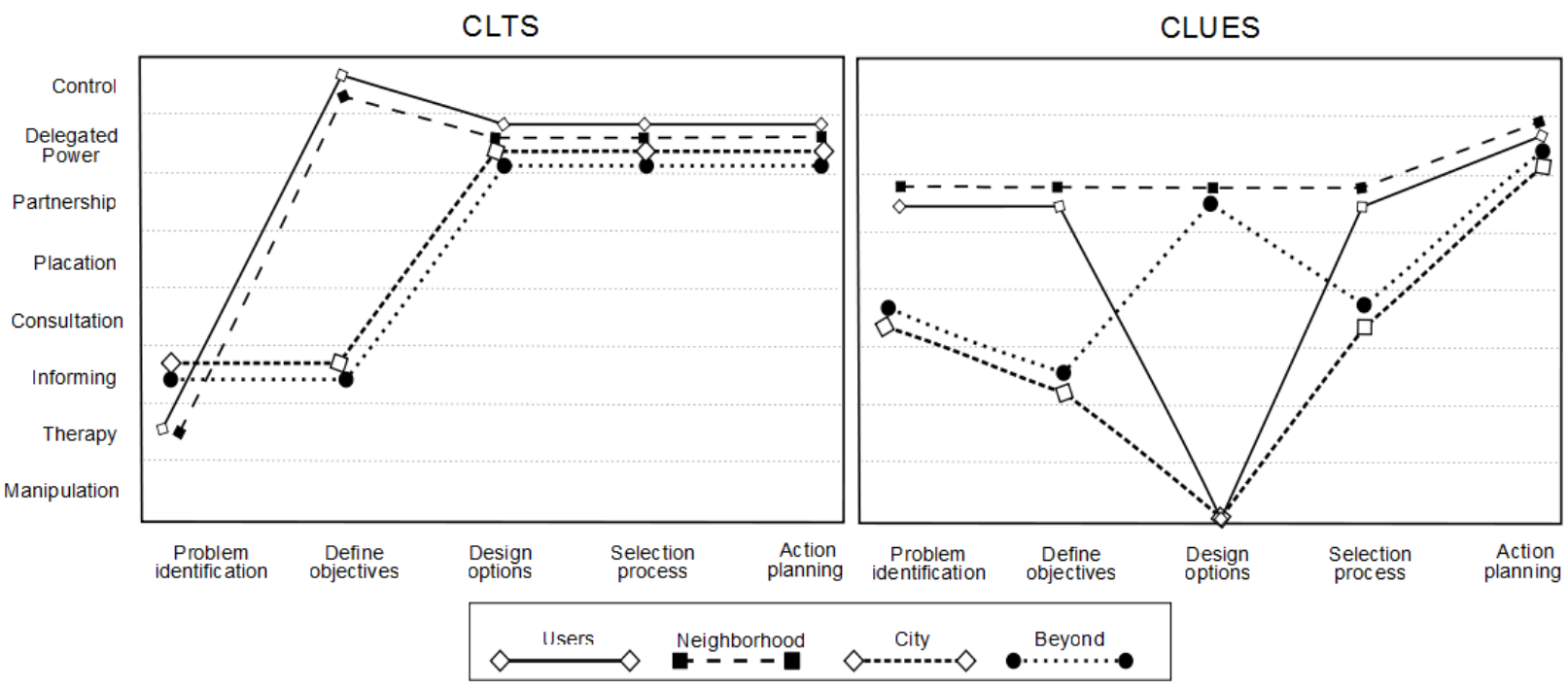

Figure 1: Participation of stakeholders in CLTS and CLUES processes. Participation is in relationship to an external facilitator in the power-holding role who is not shown in the figure.

\section{CLUES}

The CLUES steps that represent problem identification and defining objectives involve Users and Neighbourhood stakeholders working in partnership with the process leader to identify current 
deficiencies and community priorities. City and Beyond the City stakeholders participate in the consultation meetings in the first step and are then informed of community priorities (Figure 1). The design process is predominantly done in partnership between the process leader with the support of sector experts, local and national NGOs (which can be Neighbourhood/Beyond the City) and specialists (Beyond the City). The other stakeholder groups appear to be absent in this step.

Once possible service plans are identified, the process leader presents feasible options to the community for discussion and selection of the best option. Participation levels for Users thus return to the partnership levels established during the initial steps. Although it is not specified in the guidelines, it is assumed that participation levels for City and Beyond the City stakeholders will be similar to their initial involvement, i.e. consultation. The action plan is then developed through a moderated discussion with stakeholders, including community members and regulatory bodies, regarding the best way to achieve implementation. City and regulatory agencies (Beyond the City)

are specifically invited to participate in this step to clarify technical issues and institutional capacities. Each of the stakeholders thus has a specific set of issues and priorities that they bring to the discussion and they make decisions related to their capacities, i.e. delegated power.

\section{Strategic plan for sanitation in Ouagadougou (PSAO), Burkina Faso}

The process of problem identification was primarily conducted by ONEA with the help of expertled baseline studies supplemented with consultative dialogue with City and Beyond the City authorities (Figure 2). Besides households answering questions about willingness-to-pay (therapy), there is no evidence of community involvement in problem identification. Subsequent project objectives were developed under the leadership of ONEA with the consultative support from highlevel stakeholders (City and Beyond). 
As far as could be understood from interviews conducted and documentation available (WSP,

2002), the designing and selection steps were carried out by ONEA in consultation with principle stakeholders from the initial dialogues (City and Beyond). The only exception is during the designing step where technical options were designed through delegated power between experts from both CREPA (Beyond the City) and ONEA. Development of the action plan was a more participatory process. A critical element in the action plan was the use of contracted private consultants or CBOs (Neighbourhood level) to run a campaign to raise awareness among the Users of the need for sanitation and promote the ONEA technologies (informing Users). The field workers were involved in regular project which gave them more influence in the project (placation) than a strict consulting would have done.

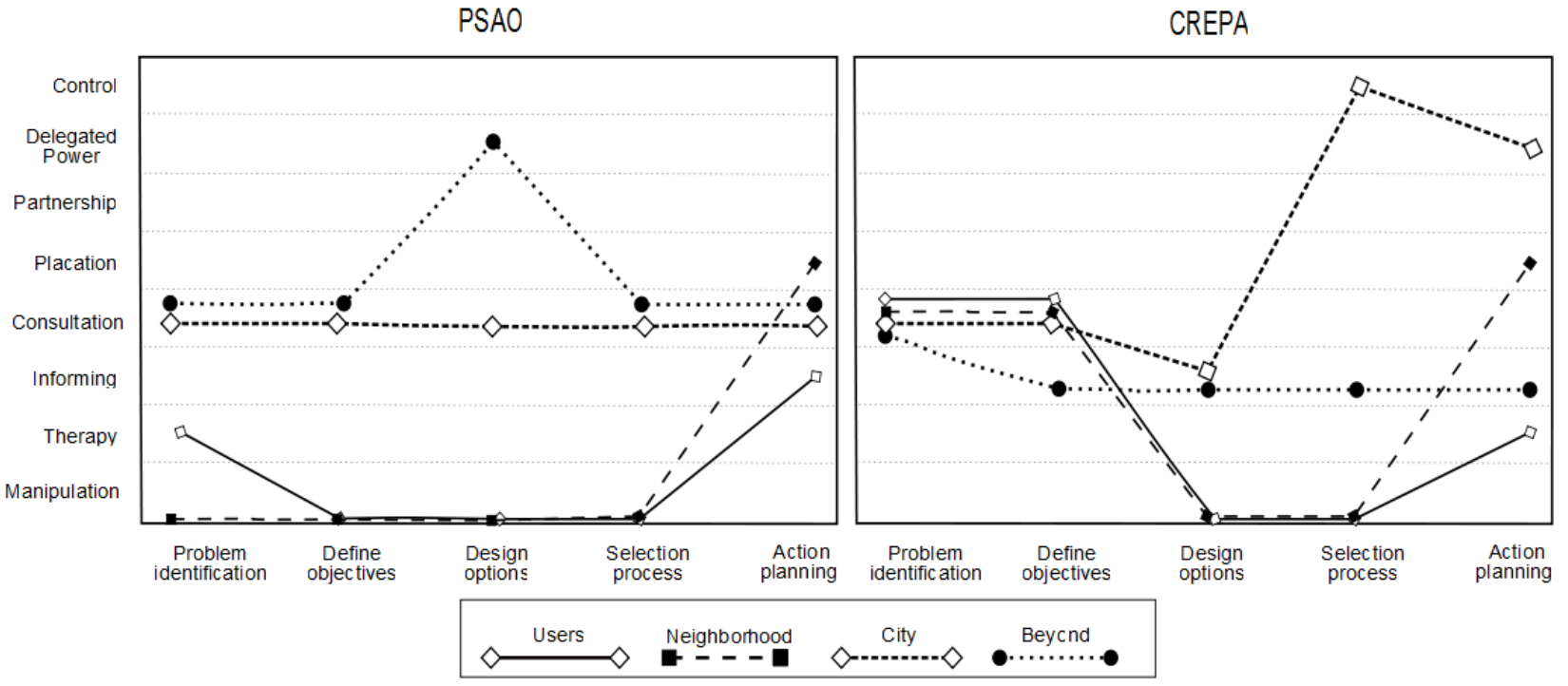

Figure 2: Participation of stakeholders in Ouagadougou (PSAO) and Tougan (CREPA) processes. Participation is in relationship to ONEA and CREPA in the power-holding roles (not shown in the figure).

\section{CREPA program for Basic Community Services in Tougan, Burkina Faso}

CREPA initiated activities in Tougan with consultations and a baseline study to identify problems 
related to water and sanitation situation from the perspective of all stakeholders. Community objectives were defined through a consultative day of public dialogue between the Users, Neighbourhood groups and municipal council (City). Partners Beyond the City were informed of the results of this dialogue but did not participate in the consultation (Figure 2).

Technical options were identified by a small groups of experts from CREPA. Although they include perspectives from the participatory activities earlier in the planning process, actual participation of other groups was low (informing at City and Beyond the City levels) or non-existent (Users/Neighbourhood) at this stage. The final descriptions of alternatives for action were presented to the municipal authorities, so as to allow them to select (control) the actions that matched the municipal priorities (Commune de Tougan, 2007). Beyond City stakeholders were informed of the decision. It is not apparent that community members participated directly in the design or selection process.

The main efforts of action planning focused on a social marketing campaign for educating and mobilizing demand for the technologies among Users (i.e. therapy), carried out by two local women's associations. The women (Neighbourhood) also participated in monitoring and feedback, thus forming part of an advisory committee for the project, although without having any official decision-making power (placation). The City maintained a key role in the action planning by delegated power sharing with CREPA. Beyond the City stakeholder remained informed of the action planning process, but did not participate directly in its development.

\section{DISCUSSION}

When using the three-tier analytical framework to compare the guidelines and implemented 
projects, it becomes clear that there is no dominant style of participation or common approach. Instead, a number of interesting similarities and differences become highlighted, which indicates a potential for improving the provision of sanitation by improving the process of sanitation planning.

First, there are striking differences between the two guidelines reviewed in this study. CLTS starts the process at a lower level of participation than CLUES, but quickly moves to high levels of control and power sharing. CLTS is also the only example studied that gives Users the delegated power during the designing step. However, both CLTS and CLUES recommend that Users and Neighbourhood groups participate at a level greater than or equal to city and government actors throughout most of the process (only exception is problem identification in CLTS). This highlights the fact that both are community-based approaches. A previous study of these two approaches suggests that a combination of them could result in an improved process (Lüthi et al., 2009). The results of this study support this argument, especially during Steps 2-3 where a combined approach might serve to smooth out dips in the participation curves (Figures $2 \& 3$ ).

Second, and in contrast to the guidelines, the analysis of the implemented projects generally shows that Users and Neighbourhood groups have a lower level of participation than city and government stakeholders. Moreover, with the exception of the municipality in the CREPA case, these practical cases also have lower participation levels for all stakeholders than was found in the guidelines. It is possible that the social structures and traditions in Burkina Faso do not encourage a more participative approach. A review of projects implemented in neighbouring Mali found that there was no tradition of community participation, and hence no expectation of it either (Paul, 1987). Further study of power structures in Burkina Faso, as well as in CLTS and CLUES projects, would be needed to determine why these differences between sanitation guidelines and sanitation practice exist. 
Third, with the exception of the CLTS approach, there is a significant decrease in participation levels during the design and selection steps of planning. A similar study of sanitation planning styles has also shown that these steps tend to be dominated by expert-driven planning procedures with limited participation and a focus on quantitative analysis (McConville et al., 2011). Although such expert-led procedures may be deemed necessary in the design of sanitation systems to assure that sanitation meets environmental and health criteria, it may also mean missed opportunities to improve the design in accordance to the needs of the population, e.g. in terms of cultural and socioeconomic dimensions of sanitation. From one perspective, the exclusion of the Users during the designing phase may not matter so much when the designing experts (i.e. the engineers) belong to the same social groups as the people receiving the designed system, as is the case in Europe and much of North America. However, in Burkina Faso this is often not the case since the experts generally live in quite different environments compared to the un-served populations for whom they are designing. Therefore, it can be argued that non-participation when designing the different options for sanitation may obstruct the overall success of the system and that reconsidering how this planning step is carried out may be a key opportunity for positive change in terms of effective and sustainable sanitation.

Fourth, previous research has provided some hints to guide the interpretation of the participation curves in Figures 1-2. A study of community participation in condominial sewer services in Brazil suggests that participation in initial planning and decision-making have greater positive impacts on the project outcomes than participation during construction and maintenance (Nance \& Ortolano, 2007). This is an interesting observation considering that the participation curves in this study show greater community-level (Users, Neighbourhood) participation during action planning than during decision-making. The exception is CLTS which calls for community-led decision-making 
throughout the process. However, CLTS has been criticized within the sector for lacking technical guidance in designing systems and weak institutional strength in urban settings (Lüthi et al., 2009). Still, the rapid success and popularity of CLTS combined with the results from Nance \& Ortolano indicate that it is worth looking closer at participation within the design and selection steps.

A final issue with the observed low levels of participation during the design and selection steps in the implemented Burkina Faso projects is how this contrasts with the increased power roles and responsibility of certain stakeholders during action planning, implementation, and finally operation and maintenance. In both projects, the household Users are expected to take ownership for operation and maintenance of latrines after the project is completed. It has been argued that participation will lead to improved user ownership and maintenance of the systems (Wood et al., 1998). Yet is it reasonable to expect user ownership of a system when these Users have only been asked about their problems and then been informed about a subsidized solution? Here, a critical question becomes when participation should take place.

\section{CONCLUSIONS}

This study has highlighted that sanitation planning has a weak tradition of including stakeholders during the design and selection steps of the planning process. However, there are indications that these are exactly the steps where participation can make a critical impact on improving project outcomes. There is evidently a need to get a clearer understanding of when and how participation should be present in sanitation planning. This study has presented a potential avenue for attaining such a capacity by providing a tool for a process-level understanding of decision-making roles and relationships between stakeholders at different points in the planning process. However, while the analytical framework developed in this study would contribute to a better understanding of the finer 
details of participation in sanitation planning, this needs to be combined with long-term evaluations of implemented projects and with studies of power relations in local contexts. In this way, it becomes possible to provide better insights regarding, not only how project outcomes may be improved, but also how participation in sanitation could be made more efficient and effective.

\section{ACKNOWLEDGEMENTS}

The authors gratefully acknowledge the help of Christoph Lüthi (Eawag) and Karim Savadogo

(CREPA) for reviewing the case descriptions for accuracy in presentation.

\section{REFERENCES}

Arnstein, S.R. (1969). "A Ladder of Citizen Participation". Journal of the American Institute of Planners, 35, $216-224$. Choguill, M.B.G. (1996). A Ladder of Community Participation for Underdeveloped Countries. Habitat International, 20(3), 431-444.

Commune de Tougan. (2007). Projet d'Assainissement Autonome et de Développement de la Commune de TOUGAN, Document de Projet. Commune de Tougan.

Hamdi, N. and Goethert, R. (1997). Action Planning for Cities: A Guide to Community Practice. John Wiley \& Sons. Chichester, UK.

International Water Association (IWA). (2006). Sanitation 21: Simple Approaches to Complex Sanitation, a Draft Framework for Analysis. International Water Association London.

Kar, K. and Chambers, R. (2008). Handbook on Community-led Total Sanitation. Institute of Development Studies at the Univ of Sussex and Plan UK, Brighton, UK.

Lüthi, C., McConville, J., \& Kvarnström, E. (2009). Community-based approaches for addressing the urban sanitation challenge. International Journal of Urban Sustainable Development, 1(1-2), 49-63.

Lüthi, C., Morel, A., Tilley, E., and Ulrich, L. (2011). Community-Led Urban Environmental Sanitation Planning (CLUES). Swiss Federal Institute of Aquatic Science and Technology (Eawag), Dübendorf, Switzerland.

McConville, J. R. (2008) Assessing Sustainable Approaches to Sanitation Planning and Implementation in West Africa. Licentiate Thesis in Land and Water Resources Engineering. KTH Architecture and the Built Environment, Stockholm, Sweden, TRITA-LWR LIC 2043.

McConville, J., Kain, J., Kvarnström, E. and Renman, G. (2011). Bridging sanitation engineering and planning: theory and practice in Burkina Faso. Journal of Water, Sanitation and Hygiene for Development, 1(3), 205-212.

Murcott, S. (2007). Co-evolutionary Design for Development: Influences Shaping Engineering Design and Implementation in Nepal and the Global Village. Journal of International Development, 19, 123-144.

Nance, E. \& Ortolano, L. (2007). Community Participation in Urban Sanitation: Experiences in Northeastern Brazil. Journal of Planning Education and Research, 26, 284-300.

Narayan, D. (1995). The contribution of people's participation. Evidence from 121 rural water supply projects. The World Bank, Washington, DC.

Paul, S. (1987). Community participation in development projects: The World Bank experience. In: World bank discussion paper no. 6. World Bank, Washington, DC.

Roma, E. and Jeffrey, P. (2010). Evaluation of community participation in the implementation of community-based sanitation systems: a case study from Indonesia. Water Science and Technology, 62(5), 1028-1036.

Stockholm Environment Institute (SEI). (2008). Proceedings from SEI/EcoSanRes2 workshop: planning and implementation of sustainable sanitation in peri/semi-urban settings - a need for development of existing tools? SEI, Stockholm, Sweden. 
Tritter, J. Q. and McCallum, A. (2006). The snakes and ladders of user involvement: Moving beyond Arnstein. Health Policy, 76, $156-168$.

Wood, S., Sawyer, R., and Simpson-Herbert, M. (1998). PHAST step-by-step guide: a participatory approach for the control of diarrhoeal disease. World Health Organization, unpublished documents WHO/EOS/98.3, Geneva.

Wright, A. (1997). Toward a Strategic Sanitation Approach: Improving the Sustainability of Urban sanitation in Developing Countries. UNDP-World Bank Water and Sanitation Program, Washington, DC, USA.

Water and Sanitation Program (WSP). (2002). Field Note: The Ouagadougou Strategic Sanitation Plan: An Holistic Approach to a City's Problems. WSP Africa Region, Nairobi, Kenya.

Water and Sanitation Program (WSP). (2007). From Burden to Communal Responsibility: A Sanitation Success Story from Southern Region in Ethiopia. Water and Sanitation Field Note, Sanitation and Hygiene Series, WSP Africa Region, Nairobi, Kenya.

WSSCC/Eawag. (2005) Household-Centred Environmental Sanitation: Implementing the Bellagio Principles in Urban Environmental Sanitation. Swiss Federal Institute of Aquatic Science and Technology (Eawag), Dübendorf, Switzerland.

Yin, R.K. (2003). Case Study Research Design and Methods, $3^{\text {rd }}$ edition. Sage, Thousand Oaks, CA, USA. 